\title{
Estimation of Remaining Life of the Orthotropic Deck of a Bridge Exposed to Extreme Traffic and Wind Actions
}

\author{
MARIIA NESTEROVA, FRANZISKA SCHMIDT \\ and CHRISTIAN SOIZE
}

\begin{abstract}
Design rules in normative documents provide additional capacity to structures by using safety coefficients and considering the worst cases of loads that in most cases never occur during the life of a structure. This extra capacity allows not only to stay on a safe side during the design operational period of structures but also to re-estimate and to extend their possible operational life. One of the most appropriate ways to estimate the remaining life of an existing structure is the extrapolation of monitored actions or load effects in critical details. The main objective of the current study is the assessment of the reliability of the steel orthotropic deck of a viaduct at the end of its design life based on limited data for traffic and static wind actions. The object of study is the Millau viaduct, a cable-stayed bridge located in Southern France, which is exposed to both, heavy traffic loads and wind loading among other actions. Monitoring data used for traffic are provided from the bridge weigh-in-motion system and include six months of data for the more loaded side of the bridge. Wind velocity and directions for the same period are taken from the structural health monitoring system of the viaduct and the nearest weather station. The methodology is based on fitting the generalized Pareto distribution to extreme stresses induced by traffic actions and by wind in order to obtain return levels at the end of the 120 years design live. Reliability indexes for the most critical part of the deck are calculated for both types of load effects separately and for their combination. Moreover, the comparison between models based on data from monitoring and on European standard models is shown.
\end{abstract}

\section{INTRODUCTION}

In a case of suspension or cable-stayed bridges, one of the main live loads to consider is the wind. European bridges are designed against wind according to European Norms (EN) [1], however, there are no rules how to reassess actual wind load to a bridge

Mariia Nesterova, Franziska Schmidt, Experimentation et modelisation for civil and urban engineering (EMGCU), Materials and Structures department (MAST), IFSTTAR, Marne-la-Vallé, 77420, Email: mariia.nesterova@ifsttar.fr; Internet: https://www.emgcu.ifsttar.fr Christian Soize, Université Paris-Est, MSME UMR 8208, UPEM, Marne-la-Vallée, 77420, France Inter-net: http://msme.u-pem.fr 


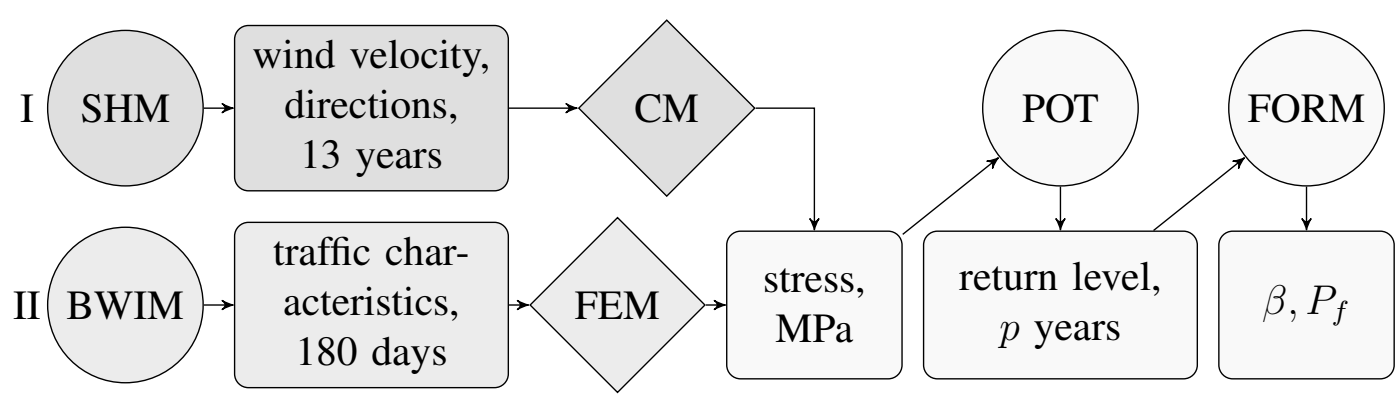

Figure 1. Steps to be taken to access reliability based on data from monitoring

in order to update the reliability of its parts (i.e. deck) based on structural health monitoring (SHM). Another question is how to assess load effects in the deck if only limited data from monitoring of wind and traffic actions are available and how to combine these actions together. A recent study [2] of the aeroelastic behavior of long-span suspension bridges under wind actions shows that the effects caused by wind may negatively influence the reliability of a bridge. Another work [3] on a combination of wind and traffic loads takes vehicles as mass points and shows that forces from higher wind velocities do not always cause a shorter life but induce large stresses in the structure if combined with heavy vehicles. In the current work, only static wind loads [4] are studied that simplifies the calculation process and makes it possible to achieve results based on available weather data. Wind velocities from SHM system are used in a computational model (CM) to assess stresses in the deck caused by the wind, see Figure 1, I. Stresses due to traffic actions are obtained from a finite element model (FEM) using data from monitoring by bridge Weigh-in-Motion (BWIM) system, see Figure 1, II.

In development of European standards for traffic actions, such as background works on EN [5], some approaches of the extreme values theory (EVT) are used for forecasting of return levels of actions [6]. EVT has been successfully used to envision the forthcoming situation of bridges [7,8] based on the long-term monitoring of traffic actions. One of the most efficient approaches of EVT to be used in wind engineering [9] is the Peaks Over Threshold (POT) method, that has proven to work well also for precipitation predictions with non-stationary data [10] or for electricity demand estimation with a time-varying threshold [11]. Here, it is used for load effects caused by heavy vehicles and for wind velocities to be used in the reliability analysis.

A correct choice of a reliability method depends on the structure, input data, initial conditions, and computational sources [12]. As the frequently used method in bridge engineering, the first order reliability method (FORM) is used [13]. A work on the reliability of bridges [14] concludes that not only fatigue but also extreme values have to be studied in the reliability analysis of bridges. Therefore, the ultimate limit state is considered here. The current study results in comparison of predicted reliability indexes $\beta$ at several return periods $p$, Figure 1, for three possible cases: traffic actions (I), wind actions (II), and combination of both (I+II).

\section{THE MILLAU VIADUCT}

Millau viaduct is a cable-stayed bridge with a steel orthotropic deck and it consists of 


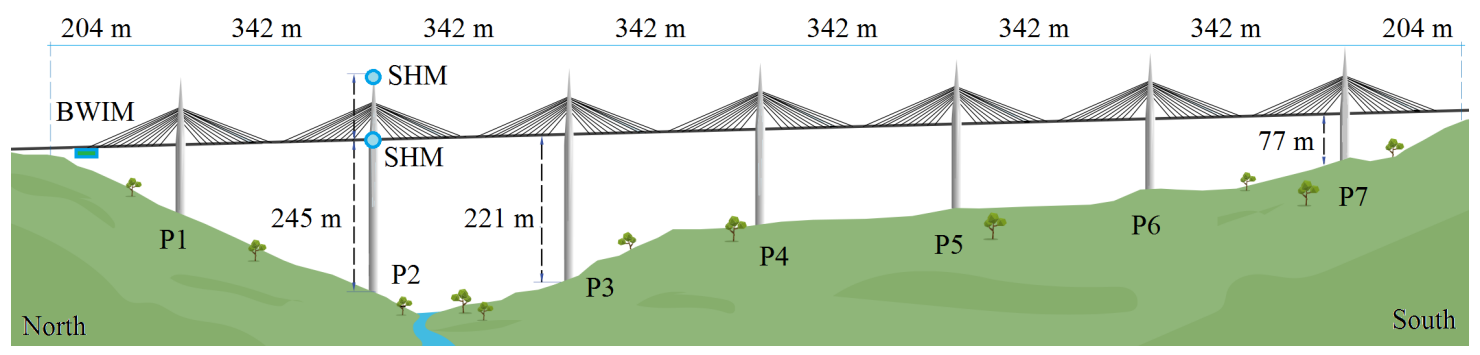

Figure 2. Millau viaduct, position of SHM and BWIM systems.

8 spans with a total length of $2460 \mathrm{~m}$, see Figure 2 . The object of this study is the deck between second and third spans accounting for wind actions on pile P2 with its pylon.

The data on traffic actions were provided from BWIM system that was located in the middle of the first span of the viaduct. It includes axle weights $[\mathrm{kN}]$ and spacing $[\mathrm{m}]$, vehicle speed [m/s], axles configuration, pavement temperature. Recordings were made between October 2016 and June 2017 with a total of 180 days of recorded traffic. Wind velocities at different heights (bottom of the pile P2, deck, top of the pylon P2) were collected by the bridge management system and a nearest national weather station with a following correlation [15]. The available period of weather data is taken for the operational period of the bridge from the end of the year 2004 until the end of 2017 (13 years). Traffic and wind loads are independent in this case as recorded wind velocities do not cross the value of $39 \mathrm{~m} / \mathrm{s}$, that would lead to a closure of the viaduct for traffic.

For the current study, the critical detail is chosen to be a welded connection between a longitudinal stiffener and the plate of the orthotropic deck that is located right under a truck wheel assuming a vehicle is passing in the middle of the slow lane, Figure 3.

\section{METHODOLOGY}

A basic limit state function $G(a)=0$, eq. (1), is defined by comparison of material resistance $R$ and stress $S(a)$ derived from structural monitoring data for a load effect $a$. The values of reliability index $\beta$ (2) and probability of failure $P_{f}$ are found using FORM.

$$
\begin{gathered}
G(a)=R-S(a) \\
\beta=-\Phi^{-1}\left(P_{f}\right)=-\Phi^{-1}\left(\int_{G(a) \leq 0} q(a) d a\right),
\end{gathered}
$$

where $q(a)$ is the probability density function of the load effect $a$ and $\Phi(a)$ is the cummulative distribution function $(\mathrm{CDF})$ of the standardized Normal distribution:

$$
\Phi(a)=\frac{1}{\sqrt{2 \pi}} \int_{-\infty}^{a} e^{-a^{2} / 2} d a
$$

Limit state functions use return values of load effects estimated for different return periods with the Peaks Over Threshold (POT) approach [6]. The method is based on fitting values of a load effect, that cross a chosen threshold, to generalized Pareto distribution (GPD) [16]. 


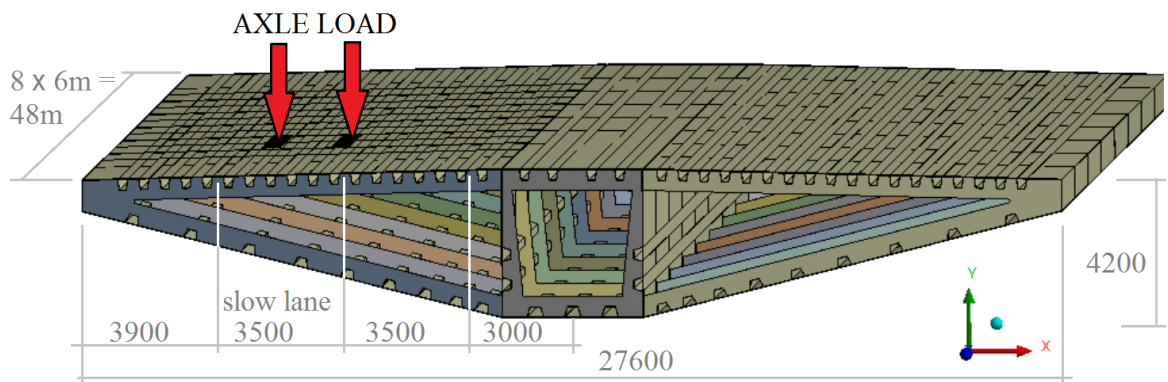

Figure 3. Finite element model of the part of the deck.

\section{Return levels of load effects}

Let $X$ be the sequence of $n$ random variables $x$ representing values of a load effect. Let $Y$ be the sequence of $m$ random variables $y$ representing exceedance of a threshold $u$ and defined by $Y=X-u \geq 0$, for every threshold excess $x \in X$ so that $x>u$. Then,

$$
H(y ; \xi ; \sigma ; u)= \begin{cases}1-\left[1+\xi\left(\frac{y}{\sigma}\right)\right]^{-1 / \xi}, & \xi \neq 0 \\ 1-\exp \left(-\frac{y}{\sigma}\right), & \xi=0\end{cases}
$$

where $\sigma>0$ and $\xi$ are shape and scale parameters of GPD $H$. The value of threshold $u$ is estimated using the graphical method [15]. Values of load effects are assumed to be identically distributed and statistically independent. The value of the $p$-observation return level $S_{\text {return }}(p)$ for the probability $P[X \leq x \mid x>u]$ with the probability of exceedance $(\mathrm{PE}) \zeta_{u}=P\{x>u\}$, is a quantile that exceeds once every $p$ observations:

$$
S_{\text {return }}= \begin{cases}S_{u}+\frac{\sigma}{\xi}\left[(p \zeta)^{-\xi}-1\right], & \xi \neq 0 \\ S_{u}+\sigma \log (p \zeta), & \xi=0\end{cases}
$$

\section{Limit state functions for traffic and wind load effects}

In the case of traffic actions, axle loads are obtained from the BWIM system installed in the bridge. The value of stress in the critical detail from each passing axle is obtained from detailed FEM of the part of the deck, Figure 3. The model takes into account the self-weight of the bridge deck with its asphalt layer, axle configuration of trucks and amplitudes of axle loads. The model is calibrated with the data from strain gauges (using signals from strain gauges recorded during the proof load test). Therefore, the limit state function (LSF) $G_{t}$ for traffic is:

$$
G_{t}=R-S_{t}\left(u_{t}, \sigma_{t}, \xi_{t}, \zeta_{t}\right)=R- \begin{cases}u_{t}+\frac{\sigma_{t}}{\xi_{t}}\left[\left(p \zeta_{t}\right)^{-\xi_{t}}-1\right], & \xi_{t} \neq 0 \\ u_{t}+\sigma_{t} \log \left(p \zeta_{t}\right), & \xi_{t}=0\end{cases}
$$

where $u_{t}$ is a threshold for maximum values of stress from each passing vehicle, $\zeta_{t} \sim$ $\mathcal{B}(0.013,0.0003)$ is the amount of load effects, that exceed the threshold, over a total amount of monitored trucks, $\sigma_{t} \sim \mathcal{L}(9.5,0.31)$ and $\xi_{t} \sim \mathcal{N}(0,0.05)$ are parameters of a fitted GPD (4), $\mathcal{B}, \mathcal{L}$ and $\mathcal{N}$ stand for Binomial, Log-normal and Normal distributions. 
In the case of wind actions, values of stress depend on the wind pressure $P=$ $0.5 \rho v^{2} A_{\text {ref }}$ that is a function of the wind velocity $v[\mathrm{~m} / \mathrm{s}]$. Hourly maximum values of $v$ are obtained from SHM together with the air temperature to evaluate the air density $\rho$. The pressure is applied to the computational model of the studied part of the viaduct in order to asses values of stresses in the considered detail. The computational model is built in Matlab software and it considers the geometry of the viaduct $A_{r e f}$, the vertical variation of the wind pressure and the stiffness of the deck. For the return values of stresses induced by the wind, LSF $G_{w}$ for wind load effects is:

$$
G_{w}=R-S_{G}- \begin{cases}u_{w}+\frac{\sigma_{w}}{\xi_{w}}\left[\left(p \zeta_{w}\right)^{-\xi_{w}}-1\right], & \xi_{w} \neq 0 \\ u_{w}+\sigma_{w} \log \left(p \zeta_{w}\right), & \xi_{w}=0\end{cases}
$$

where $S_{G}$ is the stress induced by the self weight of the structure, $u_{w}$ is a threshold for stresses calculated from hourly wind velocities (for the period of 13 years), $\zeta_{w} \sim \mathcal{B}$ $\left(0.002,2.2 \times 10^{-4}\right)$ is the amount of extreme events (velocities that exceed the threshold) over a total amount of hours $(24 \times 180$ days $), \sigma_{w} \sim \mathcal{L}(22.17,4.4)$ and $\xi_{w} \sim \mathcal{N}(0.1,0.16)$ are parameters of the fitted GPD, (4). The LSF $G_{C}$ for the combination of loads for the case when $\xi_{t} \neq 0$ and $\xi_{w} \neq 0$ :

$$
G_{C}=R-\left(u_{t}+\frac{\sigma_{t}}{\xi_{t}}\left[\left(p \zeta_{t}\right)^{-\xi_{t}}-1\right]+u_{w}+\frac{\sigma_{w}}{\xi_{w}}\left[\left(p \zeta_{w}\right)^{-\xi_{w}}-1\right]\right)
$$

The summary of random variables for each LSF, (6), (7) and (8), based on described approaches is given in Table I.

\section{RESULTS OF RELIABILITY ANALYSIS}

Three failure modes are observed in the current study: 1. extreme traffic load on one side of the deck (T), 2. extreme static wind load normal to the deck (W), 3. unfavorable combination of traffic and the wind. It is important to note that the combination of both actions is conditioned by the wind speed, that does not cross the value of $140 \mathrm{~m} / \mathrm{s}$ that causes the closure of the bridge for traffic $(\mathrm{W}+\mathrm{T})$.

The results of reliability analysis are listed in Table II. It presents values of the reliability index $\beta$ and the probability of failure $P_{f}$ for three different return periods:

TABLE I. RANDOM VARIABLES FOR THE RELIABILITY ANALYSIS

\begin{tabular}{crcccc}
\hline Case & \multicolumn{2}{c}{ Random variable } & Distribution & Mean & CoV \\
\hline \hline resistance & steel strength & $R, \mathrm{MPa}$ & Log-normal & 400 & 0.05 \\
\hline self-weight & stress & $S_{G}, \mathrm{MPa}$ & constant & 2.5 & 0 \\
\hline traffic & threshold & $u_{t}$ & constant & 27 & 0 \\
& shape & $\xi_{t}$ & Normal & 0 & - \\
& scale & $\sigma_{t}$ & Log-normal & 9.5 & 0.03 \\
& $\mathrm{PE}$ & $\zeta_{t}$ & Binomial & 0.013 & 0.02 \\
\hline wind & threshold & $u_{w}$ & constant & 152 & 0 \\
& shape & $\xi_{w}$ & Normal & 22.17 & 0.2 \\
& scale & $\sigma_{w}$ & Log-normal & 0.1 & 1.58 \\
& $\mathrm{PE}$ & $\zeta_{w}$ & Binomial & 0.002 & 0.02 \\
\hline
\end{tabular}


one year, 50 years (in order to compare with EN return values), 120 years (the end of the design operational life of the viaduct). For the value of 50 years, it provides a comparison between reliability indexes derived from monitoring data with those from design load models. The last column shows reliability levels required by EN [17].

\section{CONCLUDING REMARKS}

The result of the current study shows the reliability of a welded connection between the plate and a longitudinal stiffener of the steel orthotropic deck of the Millau viaduct. Three load cases were observed: static wind, heavy vehicles and their combination.

The evaluation of the detail after one year from monitoring shows that the reliability index is high in all cases. It is so because the probability of occurrence of strong winds or heavy trucks with a highly overweighted axle is low. For the 50 years return period, design load model for traffic gives a low probability of failure, however, in reality, the presence of several heavy vehicles on the deck negatively affect the reliability index. It shows the importance of structural monitoring with following updating of design load models during the operational life of a structure.

Another conclusion is that static wind actions alone do not affect much the deck, however, if combined with traffic, they contribute significantly into its reliability. So, both types of action, traffic and climatic, should be considered in the reliability analysis of an orthotropic deck.

The probability of failure due to the combination of traffic and wind loads from monitored actions is lower than the value obtained with the design load models. It confirms that the design standards stay on the safe side. It is found that the reliability index at the end of the design life of the viaduct (120 years) is high enough. However, results for the case of fatigue should be taken into consideration in order to make further conclusions on the reliability of welded details of the orthotropic deck of the viaduct.

\section{ACKNOWLEDGEMENTS}

This project has received funding from the European Union's Horizon 2020 research and innovation programme under the Marie Sklodowska-Curie grant agreement No 676139. The grant is gratefully acknowledged.

The BWIM measurements for the Millau viaduct were obtained with the help from

TABLE II. RESULTS OF THE RELIABILITY ANALYSIS

\begin{tabular}{|c|c|c|c|c|c|c|c|c|}
\hline \multirow{2}{*}{$\begin{array}{l}\text { return } \\
\text { period }\end{array}$} & & \multicolumn{3}{|c|}{ Monitoring + EVT } & \multicolumn{3}{|c|}{ Design models, $[1,18]$} & \multirow{2}{*}{$\begin{array}{c}\text { EN [17] } \\
\text { value }\end{array}$} \\
\hline & & $\mathrm{W}$ & $\mathrm{T}$ & $\mathrm{W}+\mathrm{T}$ & $\mathrm{W}$ & $\mathrm{T}$ & $\mathrm{W}+\mathrm{T}$ & \\
\hline 1 & $\beta$ & 21.9 & 21.8 & 9.9 & & - & & 4.7 \\
\hline year & $P_{f}$ & $\approx 0$ & $\approx 0$ & $10^{-23}$ & & - & & $1.3 \times 10^{-6}$ \\
\hline 50 & $\beta$ & 21.8 & 14.4 & 6.2 & 8.9 & 24.3 & 5.3 & 3.8 \\
\hline years & $P_{f}$ & $\approx 0$ & $\approx 0$ & $3.3 \times 10^{-10}$ & $10^{-18}$ & $\approx 0$ & $10^{-7}$ & $7.2 \times 10^{-5}$ \\
\hline 120 & $\beta$ & 21.7 & 11.4 & 4.5 & & - & & \\
\hline years & $P_{f}$ & $\approx 0$ & $10^{-30}$ & $2.0 \times 10^{-6}$ & & - & & \\
\hline
\end{tabular}


CESTEL, Slovenia and EIFFAGE, France, which is highly appreciated.

\section{REFERENCES}

1. European Committee for Standardisation. 2005. EN 1991-1-4: Eurocode 1: Actions on structures - Part 1-4: General actions - Wind actions.

2. Arena, A., W. Lacarbonara, D. Valentine, and P. Marzocca. 2014. "Aeroelastic behavior of long-span suspension bridges under arbitrary wind profiles," Journal of Fluids and Structures, 50:105-119.

3. Zhang, W., C. Cai, F. Pan, and Y. Zhang. 2014. "Fatigue life estimation of existing bridges under vehicle and non-stationary hurricane wind," Journal of Wind Engineering and Industrial Aerodynamics, 133:135-145.

4. Davenport, A. 1993. "The generalization and simplification of wind loads and implications for computational methods," Journal of Wind Engineering and Industrial Aerodynamics, 46:409-417.

5. Jacob, M. 1990, "Methods for the prediction of extreme vehicular loads and load effects on bridges," .

6. Coles, S. 2001. An Introduction to Statistical Modeling of Extreme Values, Springer Science \& Business Media.

7. Treacy, M., E. Brhwiler, and C. Caprani. 2014. "Monitoring of traffic action local effects in highway bridge deck slabs and the influence of measurement duration on extreme value estimates," Structure and Infrastructure Engineering, 10(12):1555-1572.

8. Zhou, X. Y. 2013. Statistical analysis of traffic loads and their effects on bridges, phdthesis, Universit Paris-Est.

9. Agarwal, P. and L. Manuel. 2009. "Simulation of offshore wind turbine response for longterm extreme load prediction," Engineering Structures, 31(10):2236-2246.

10. Roth, M., T. Buishand, G. Jongbloed, A. Klein Tank, and J. van Zanten. 2014. "Projections of precipitation extremes based on a regional, non-stationary peaks-over-threshold approach," Weather and Climate Extremes, 4:1-10.

11. Sigauke, C. and A. Bere. 2017. "Modelling non-stationary time series using a peaks over threshold distribution with time varying covariates and threshold," Energy, 119:152-166.

12. Morio, J., M. Balesdent, D. Jacquemart, and C. Vergé. 2014. "A survey of rare event simulation methods for static input-output models." Simulation Modelling Practice and Theory, 49:287-304.

13. Klüppelberg, C., D. Straub, and I. Welpe. 2014. Risk - A Multidisciplinary Introduction., Springer.

14. Ghasemi, S. and A. Nowak. 2017. "Target reliability for bridges with consideration of ultimate limit state." Engineering Structures, 152:226237.

15. Nesterova, M., F. Schmidt, and C. Soize. 2019. "Probabilistic analysis of the effect of the combination of traffic and wind actions on a cable-stayed bridge." Bridge Structures.

16. Pickands, J. 1975. "Statistical Inference Using Extreme Order Statistics," The Annals of Statistics, 3(1):119-131.

17. European Committee for Standardisation. 2002. EN 1990: Eurocode: Basis of structural design.

18. European Committee for Standardisation. 2003. EN 1991-1-2: Eurocode 1: Actions on structures - Part 2: Traffic loads on bridges. 